\title{
A Sustainable Evaluation Method for a Tourism Public Wayfinding System: A Case Study of Shanghai Disneyland Resort
}

\author{
Wenying Zhang ${ }^{1}$, Lian Zhu ${ }^{1}\left(\mathbb{D}\right.$, Zixuan Zhang ${ }^{1}$, Zhan Zhang ${ }^{2, *} \mathbb{C}$ and Linjun Lu ${ }^{1} \mathbb{D}$ \\ 1 Transportation Research Center, Department of Transportation Engineering, Shanghai Jiao Tong University, \\ Shanghai 200240, China; elsie1995@sjtu.edu.cn (W.Z.); zhulian006@sjtu.edu.cn (L.Z.); \\ zzxsphinx@sjtu.edu.cn (Z.Z.); linjunlu@sjtu.edu.cn (L.L.) \\ 2 School of Design, Shanghai Jiao Tong University, Shanghai 200240, China \\ * Correspondence: zhanzhang@sjtu.edu.cn; Tel.: +86-138-1845-8042
}

Received: 14 August 2020; Accepted: 30 September 2020; Published: 14 October 2020

\begin{abstract}
The traditional method of designing wayfinding systems has been used in tourism management for decades. However, the absence of quantitative evaluations for the wayfinding system at tourist resorts may affect information transmission and cause visitors to feel lost. This article proposes a quantitative approach and applies it to the wayfinding system at the Shanghai Disneyland Resort from 2017 to 2019, where the layouts and the contents of wayfinding signboards are systematically evaluated. The analytic hierarchy process is used in conjunction with expert advice to rank 11 elements of content design, and four reasonable indices are calculated to explore the spatial-topological relationships at the tourism resort. According to both the field and expert investigation and tourists' responses to designed questionnaires, the results show that this method containing content and layout evaluation can enhance tourist satisfaction in certain aspects, thus helping to improve tourism management by considering important indices in wayfinding signage design and modification.
\end{abstract}

Keywords: wayfinding system; analytic hierarchy process; topological layout

\section{Introduction}

Fuzzy information adversely affects the activities of tourists, so tourism managers have begun realizing the importance of the wayfinding system design in recent years [1]. The public wayfinding system is a standard instruction system for spatial environments in open areas that is meant to help people find information on their destinations [2]. The wayfinding system design is an overall collection formed by both the signboard contents and its layouts in a certain area, including different elements such as the design of color, font, height, and size of a single signboard, and the location structure and density control of a large amount of wayfinding signs.

Based on these premier studies, this article proposes a quantification evaluation method for scoring both the content and layout of the wayfinding system at scenic spots. Eleven content indices of three signboard types are calculated by an analytic hierarchy process, and the topological metrics for the layout design is proposed, where the parameters and calculation formulae are preliminarily defined. In addition, we investigate the effects in information conveyed by the signage on tourist preferences and experts' recommendations, and thus evaluate the specific Disneyland tourist site based on quantitative analysis.

The core area of the Shanghai International Tourism Resort (Shanghai Disneyland) covers an area of about seven square kilometers, of which the first phase spans 3.9 square kilometers. The core area includes a theme park and hotel, retail catering and entertainment, transportation, and municipal 
supporting facilities. Rail transit line 11 will service the area soon, and Rail transit line 2 will service it in the long term. The two lines share a rail transit station in the area. The main construction of Phase I of the core area includes amusement park facilities (theme park), the Central Lake and Weicheng River, retail catering and entertainment, a themed hotel, public parking lot (tourist parking lot), public transportation facilities, offices (management service center), and municipal facilities. Our study selected working days and weekends as special days, and we then carried out the field and questionnaire surveys.

The Shanghai Disneyland Resort had been open for a year before an improvement scheme was implemented to it. The public information guidance system for tourists has played a crucial role in its operations, and its shortcomings have gradually been realized with experience. During the construction of the guidance system, there were significant differences in design methods and construction processes. Multiple construction units can easily lead to a lack of continuity or inconsistency of informational signage. According to our investigation, the park had 46 indication signs, 9 positioning maps, 7 wall signs, 2 commercial signs, 7 bus station signs, 17 signs showing the names of roads, 2 braille maps, and 6 summarizing signs for a total of 96 positioning sites. After getting feedback from tourists, the optimization evaluation was adjusted locally. The field investigation yielded a complete record of guiding signs within the scope of the wayfinding system of the Shanghai International Tourism Resort. According to CAD (computer aided design) drawings provided by the Disneyland sponsors, we have measured and evaluated the topological layout of signboards and coordinates.

Our work timeline is as follows. At the beginning of 2017, the method was determined, and experts were invited to determine the coefficient and measurement standard. The preliminary survey was conducted in June 2017, and later the calculation was completed, and the revised scheme was submitted in December. In June 2019, a random survey was conducted in the Disneyland Park on tourists' satisfaction with the guidance system adjusted according to the improved scheme. By comparison, the values of indicators were rising, and the improvement scheme has achieved good results.

The remainder of this paper is organized as follows. Section 2 introduces research on guidance systems in recent decades, and Section 3 details our proposed method. Section 4 introduces the evaluation of the Shanghai Disneyland Resort and the comparison of tourist satisfaction before and after modification. Section 5 contains the conclusions of this study.

\section{Literature Review}

According to the literature review, the past research on tourist wayfinding systems can be divided into two parts-one is the discussion and design on the content elements, and another is the information transmission achieved by the layout of the wayfinding system. The current research has been achieved to select the sign evaluation factors, put forward the layout hierarchy, and establish the comprehensive evaluation index as the representative of the system performance [3]. The researchers examined the integrity and effectiveness of unique symbolic information by using the analytic hierarchy process, and in this context, the spatial syntax [4], the design of route-finding navigation systems [5], and a redefinition of spatial information [6] have also been conducted. As a component of urban planning, guidance systems have attracted considerable research attention in the last century [7]. The isotype system movement (International System of Typographic Picture Education) launched in the 1920s was the first to emphasize the importance of creating a system of visual design [8]. In the 1960s, Lynch proposed a systematic concept of the urban guidance system and discussed several solutions to relevant problems [9]. Golledge proposed three levels of spatial knowledge and spatial knowledge acquisition, where the foundation of spatial analysis has been formed [7]. Research by Michon, Denis, and Tom has shown that people move around using landmarks on road signs [6]. Meilinger and Knauff investigated human wayfinding and knowledge acquisition in urban environments [10]. The participants in their study were required to retrace two routes learned either from route maps or from verbal directions. Grabler, Agrawala, and Sumner discussed the automatic design of maps of tourist routes in his work [11]. One study by Wiener, Büchner, and Hölscher has shown that knowledge of specific target 
locations, paths, and the overall environment can help determine the behavior and cognitive strategies that can be applied to perform road finding tasks [12]. Dai focused on the design of directional information signs for passengers in an integrated transport hub using the concept of utility [13]. Kühl, Stebner, and Navratil examined the effects of different visualization models on the acquisition of collateral routes and the surveyed knowledge during an assisted tour [14]. Schewering, Krukar, Li, Anacta, and Fuest proposed a computer-based pathfinding method that supports user positioning through a location-based pathfinding navigation system that uses spatial learning and cognitive mapping [15]. Recent research has focused on guidance systems for pedestrians and vehicles. Studies have been conducted on the objective factors influencing guidance indicators, the identification of the guidance system by traffic, and the application of topological networks using route-related and spatial relationships [16]. An effective navigation system can guide people to their destination and improve tourist safety [17].

At the same time, several essential topological elements of public guidance systems have been defined by referring to research on the topologies of traffic networks. Graph theory was first applied to research on transportation in the 1960s by Bodino [18]. Chown, Kaplan, and Kortenkamp proposed a wayfinding system with the fundamental goals of this work being to examine how the wayfinding process is integrated into general cognition [19]. Topological relations refer to the spatial relationships among elements, such as points and edges, in a topological graph, and include connectivity, inclusion, and adjacency [20]. The topological structure of the guidance system is like the topological network of urban traffic [21]. There are several bottlenecks in current research. Most studies have focused on either the elements of identification or the overall layout [22]. Both system planning and the design of the signage remains essential for a successful guidance system; thus, a good measurement model should combine them [23]. Moreover, most research in this field has addressed specific cases, because of which improvements to conventional methods have rarely been proposed. Software or computer programming is mostly used to design the guidance system, and few scholars have developed measurement indicators and calculation formulae. Past work in the area reveals a pyramid structure of problems with guidance systems. At the top, the most significant problem in this context is accidents caused by the guidance system, such as stampeding and improper evacuation of public areas in case of emergency [24]. A deeper layer represents the tourists' sense of loss, and an inability to find their desired spots. The next layer features unreasonable information transmission, and the deepest layer is constituted by the unreasonable design of the topological network and the elements of signage, and the last is the fundamental problem requiring a solution. Quantitative models have been widely used for evaluation and optimization [25], so we decided to provide a quantitative topological method as an improvement method over the traditional design.

\section{Methodology}

\subsection{Method to Evaluate Layout of Signage}

We evaluated the contents of three types of signs in the park according to the opinions expressed which can be seen in Figure 1 by subjects in the interviews and expert surveys. To assess the layout of the signs, we calculated the values of six indicators according to the horizontal and vertical coordinates of signs representing maps of the park [26]. The calculation process was as follows: (1) investigations of signs in the map; (2) calculation of indicators according to the proposed formulae according to the data provided by the park management personnel, thus we can get values of scenic spot popularity $\left(c_{j}\right)$ and right of way $\left(\mathrm{w}_{\mathrm{k}}\right)$. The value of radiation $\left(\mathrm{l}_{\mathrm{ik}}\right)$ was limited to $50-200 \mathrm{~m}$ according to the reasonable sight distance standard [27]; (3) normalization of index values according to the standard index values to obtain the quantification results [28]. 


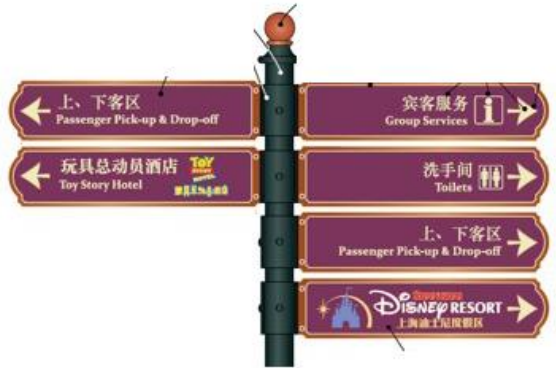

(a)The general view of indicating signs

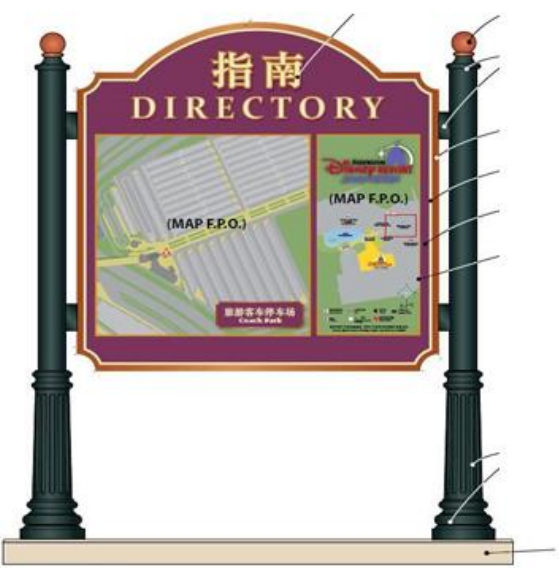

(c)The general view of positioning signs

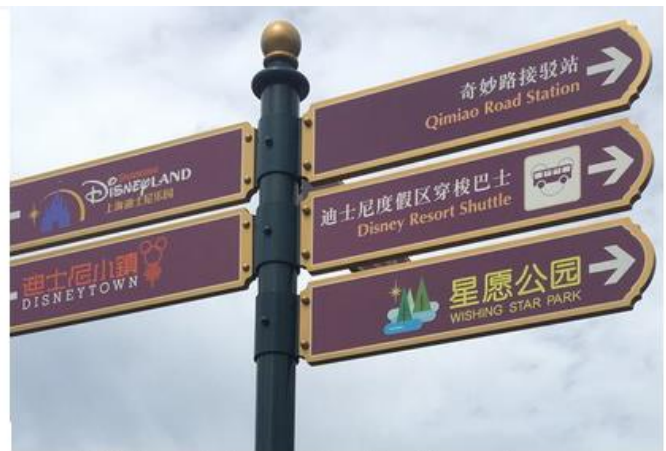

(b)The picture of indicating signs

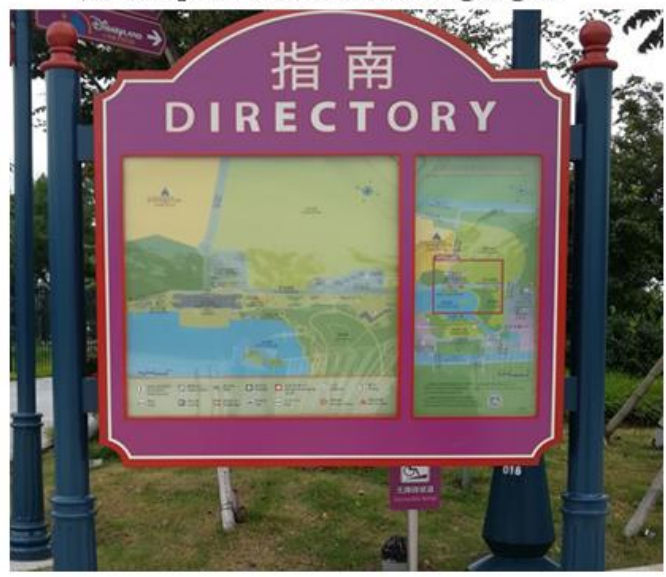

(d)The picture of positioning signs

Figure 1. A general view of the signage in Shanghai Disneyland Resort, and a picture from our field investigation (a-d).

The main guiding elements of the public information guiding system are graphic signs, text signs, plane sketch maps, information boards, block guiding maps, and portable printed maps. Guidance signage can be divided into three categories according to function: indication signs, positioning signs, and information plates. The layout of guide signs in the study area is shown in Figure 2.

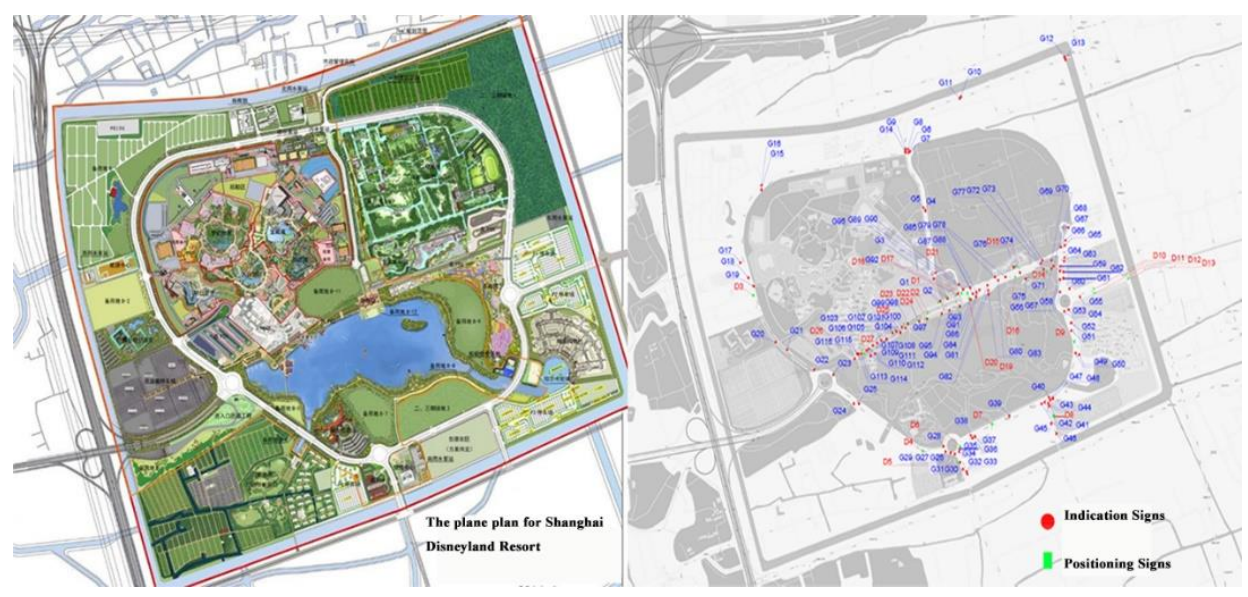

Figure 2. Locations of signage in Shanghai Disneyland Resort.

Indication signs are the most common form of signage in tourist areas. They show the directions and distance to one or several destinations; positioning signs provide distance-related information on all destinations within a specific range, and plane information signs provide the overall layout 
of the given destination [29]. The research object of this project was the static guidance system of signs for pedestrians in peripheral public areas, excluding signage for motor vehicles and dynamic electronic signs.

The average degree of attraction of indication guidance (AATT) is an indicator that measures the attractiveness to tourists of scenic spots indicated by the signs. Tourists are more likely to go to more popular places, and more signs should be used to guide them to such areas [13]:

$$
A A T T=\frac{\propto_{1}}{N(N+1)} \sum_{i, j \in N, i \neq j} c_{j} \cdot F_{1}
$$

where $c_{j}$ is the degree of attraction of destination $j$, and is related to the flow of people and the importance of the destination in planning as determined by the staff, and $\mathrm{N}$ is the number of informational signs i. That is, an indication sign may have information on directions to one or more areas. F represents whether directions for destination $\mathrm{j}$ are on the given sign. $\mathrm{F}=0$ or $\mathrm{F}=1$, and $\propto_{1}$ is the adjustment factor for calculation.

The average distance of indication guidance (ADIS), according to past research [12], is used to measure whether the distance between the location of the sign and the destination indicated is reasonable:

$$
A D I S=\frac{\alpha_{2}}{N(N+1)} \sum_{i} \sum_{j} \frac{1}{d_{i j}} \cdot F_{2}
$$

where $d_{i j}$ is the Euler distance between sign $i$ and destination $j$. N represents the number of informational items on sign i. F represents whether destination $j$ is on the given sign. $F=0$ or $F=1$, and $\propto_{2}$ is the adjustment factor for calculation.

The average density of indication of the road where a sign is located (ADEN) represents the degree of reasonableness of the density of the signboard along the road as classified by the volume of traffic:

$$
A D E N_{S_{i}, S_{p}}=\frac{\propto_{3}}{M(M+1)} \sum_{0, k \in G} w_{k} \times F_{3}
$$

where $S_{i}$ represents the indication signs, and $S_{p}$ is the positioning signs. $w_{k}$ is the factor to assess traffic volume on road $\mathrm{k}$. M represents the number of indication or positioning signs. $\mathrm{F}$ represents whether destination $\mathrm{j}$ is listed on this sign. $\mathrm{F}=0$ or $\mathrm{F}=1$, and $\propto_{3}$ is the adjustment factor for calculation:

$$
K=a K_{1}+b K_{2}
$$

where the coefficients a and $b$ represent the proportions of the signboard occupied by the pointing and positioning functions, respectively, in the entire scope of evaluation, that is, the overall layout is added proportionally by the results of the indices of two separate arrangements.

The average informational coefficient of the indication sign network (AINT) evaluates the reasonableness of the density of all signboards in the area by measuring the coverage of guidance information across the entire region:

$$
\operatorname{AINF}_{S_{i}, S_{p}}=\frac{\alpha_{4} \sum_{i}\left(\sum_{k} l_{i k} \times w_{k}\right)}{M(M+1)}
$$

where $S_{i}$ represents indication signs, and $S_{p}$ is positioning signs. $l_{i k}$ is the sum of the lengths of the range of radiation of the sign on road $\mathrm{k}$, which depends on the visual distance of human eyes. M represents the number of informational items on indication sign $i$, and $\propto_{4}$ is the adjustment factor for calculation.

The optimal solution obtained by using a single target may be less effective under another standard. In practice, people are more willing to accept a plan that takes all perspectives into account, rather than a one-sided optimal plan. Therefore, the design of indices of the guidance system should consider an excellent guidance effect, a short distance, and a reasonable layout density on average [30]. 
To simplify the calculation, the following preliminary assumptions were made for the study area: (1) We assumed an exponential network (not a power law distribution), homogeneous nodes, smooth roads, and homogeneous road sections excluding passenger flow. (2) Each type of sign had the same format excluding its content. (3) Scenic spots, intersections, and entrances could be used as target points in the formulae for indices but were calculated separately in practice to be refined and adjusted. (4) When studying the topological relationship between the signboards and the target point, a directed weighted graph was used; when considering the topological metrics, an undirected weighted graph was used.

\subsection{Method to Evaluate Content of Signage}

A system to identify tourist attractions usually offers the following kinds of identification: location identification, guidance identification, plane schematic/block guidance, information board, portable printed matter, and safety-related guidance. For different identification types, the elements for evaluation should be designed differently [31] According to the qualitative description in the national standard, we propose a measurement scheme consisting of four categories and 11 indicators to determine the quantitative results of the design of the marking systems for convenience, secure identification, continuity, and accuracy [4].

The analytic hierarchy process (AHP) is as follows. Layer 1 is the content evaluation of the guidance system (A), which is the goal of the entire AHP [32]. Layer 2 is the criterial layer consisting of text content (B1), location-related text (B2), typesetting design (B3), and features for the disabled (B4). These are used to assess the content of the signage on different criteria. Layer 3 features the estimation of the 11 indicators (C1-C11), shown in Table 1, and Layer 4 is a schematic layer where four design standards proposed by researchers are ranked in the guidance system: convenience (D1), ease of recognition (D2), continuity (D3), and accuracy (D4).

For the specific value and importance of the value matrix in the analytic hierarchy process, we consulted nearly 20 experts with over five years of experience in areas, who are related to Disney's operations management team, the corresponding government management department, regional planning department, and road traffic management department in Shanghai. These experts are invited to assign values according to the relative importance of each factor in each layer to form the judgment matrix. After interviews and on-site scoring, the relative importance of each element in the judgment matrix was determined by the expert opinion method (Delphi method), and the importance of each index was scaled on Saaty's 1-9 scale [33]. The Delphi method is mainly used to determine the following values: (1) The initial level of each factor in AHP, using Saaty's nine-level scaling method, and determining the design of four levels framework. (2) According to the evaluation criteria of the AHP method and topological coefficient method, $150 \%$ is the result of comparison with the benchmark evaluation score. The benchmark evaluation score is determined by 20 experts with urban planning and park design backgrounds after three rounds of scoring. The discussion results show that $100 \%$ of the benchmark score is in line with the standard, and 1.5 times of the benchmark score or more is preferred. (3) According to the statistics of the last five years, the coefficient of the spatial topological index is determined, such as the heat of attraction, the height of right of way, and so on.

In the AHP evaluation index, $\mathrm{WA}(\mathrm{B})=(0.3937,0.0752,0.3937,0.1374)$, the consistency ratio (C.R.) factors of $\mathrm{WB}(\mathrm{C})$ and $\mathrm{WC}(\mathrm{D})$ were all less than 0.1 , and the value of $\mathrm{WA}(\mathrm{D})=(0.246,0.279,0.183,0.191)$. By calculating the total rank consistency ratio C.R. $<0.1$, the results were determined to be credible. 
Table 1. Elements of content selection and interpretation in the analytic hierarchy process.

\begin{tabular}{|c|c|c|}
\hline Category $^{1}$ & Assessment Elements & Explanation \\
\hline \multirow{4}{*}{ Text Content (B1) } & Information Accuracy (C1) & Emphasis is placed on conveying accurate information on a single sign (in terms of direction, target, and distance). \\
\hline & Information Conciseness (C2) & Emphasizes the simplicity of conveying information on a sign to ease the burden on tourists. \\
\hline & Unified Standard (C3) & The standard unification of naming in the public information guidance system is emphasized. \\
\hline & Categorization (C4) & Emphasis is placed on the hierarchical ordering of information on signboards, prioritizing more critical information. \\
\hline \multirow{2}{*}{ Text Location (B2) } & Sight Distance (C5) & The visibility distance of a single sign should not exceed its maximum value. \\
\hline & Height (C6) & Height should be set-up to meet the standard requirements. \\
\hline \multirow{2}{*}{ Typesetting Design (B3) } & Color (C7) & For items of information with different degrees of importance, we should consider the diversity of color/color contrast. \\
\hline & Size (C8) & The size of the words, numbers, and symbols should be in line with the industry standard. \\
\hline \multirow{3}{*}{ Disabled Care (B4) } & Distance Recognition (C9) & For guiding signs only, the distance between signs presenting location information is emphasized. \\
\hline & Proportions (C10) & The scale is checked to determine if it is appropriate for the plane sketch/block guidance map. \\
\hline & Humanistic Concern (C11) & For the plane sketch/block guidance map, this shows whether there is braille in the picture. \\
\hline
\end{tabular}

${ }^{1}$ The selection of elements in consultation with experts and government departments. 
In the schematic layer, the proportions of Layer $\mathrm{D}$ were as follows: convenience, 0.246 ; ease of identification, 0.279 ; continuity, 0.183; and accuracy, 0.191 .

Through the above AHP results in Tables 2 and 3, the preliminary conclusions drawn were as follows:

1. The most important parts in the design of the sign system were the accuracy and size of the information, respectively. Following them in importance was the color design of the information board, which also belongs to the typesetting design part and accounted for more than $10 \%$.

2. Distance identification ( $8.91 \%)$ and a unified standard $(8.59 \%)$ should be attended to as well. At present, directional signs cannot guarantee the accuracy of distance identification, and lack of unified signs for a scenic spot, which leads to the differences of scenic spots in different places, the phenomenon of inconsistent signs in the same area, and aggravates the sense of loss of tourists.

3. The calculations of the AHP showed that the most important factor was ease of identification, followed by convenience. In planning identification systems, the person in charge is likely to pay attention to the continuity and accuracy of complex information while ignoring the most critical demands of tourists.

Table 2. The coefficients and the results of signage content in the analytic hierarchy process.

\begin{tabular}{|c|c|c|c|c|c|c|}
\hline \multicolumn{7}{|c|}{ Results for Layers c and d: Judgment Matrix } \\
\hline$W_{c i j}\left(D_{i}\right)$ & $\mathrm{C}_{1}$ & $\mathrm{C}_{2}$ & $\mathrm{C}_{3}$ & $\mathrm{C}_{4}$ & $\mathrm{C}_{5}$ & $\mathrm{C}_{6}$ \\
\hline $\mathrm{D}_{1}$ & 0.059 & 0.073 & 0.558 & 0.132 & 0.248 & 0.292 \\
\hline $\mathrm{D}_{2}$ & 0.254 & 0.560 & 0.249 & 0.216 & 0.531 & 0.506 \\
\hline $\mathrm{D}_{3}$ & 0.158 & 0.141 & 0.096 & 0.534 & 0.163 & 0.084 \\
\hline $\mathrm{D}_{4}$ & 0.529 & 0.226 & 0.096 & 0.119 & 0.059 & 0.118 \\
\hline Lamdama & 4.073 & 4.131 & 4.043 & 4.270 & 4.285 & 4.284 \\
\hline C.R. $<0.1$ & 0.025 & 0.045 & 0.015 & 0.094 & 0.099 & 0.099 \\
\hline Wcij(Di) & $\mathrm{C}_{7}$ & $\mathrm{C}_{8}$ & $\mathrm{C}_{9}$ & $\mathrm{C}_{10}$ & $\mathrm{C}_{11}$ & \\
\hline $\mathrm{D}_{1}$ & 0.058 & 0.545 & 0.076 & 0.222 & 0.478 & \\
\hline $\mathrm{D}_{2}$ & 0.124 & 0.277 & 0.261 & 0.564 & 0.276 & \\
\hline $\mathrm{D}_{3}$ & 0.038 & 0.099 & 0.513 & 0.082 & 0.144 & \\
\hline $\mathrm{D}_{4}$ & 0.014 & 0.079 & 0.150 & 0.132 & 0.102 & \\
\hline Lamdama & 4.161 & 4.222 & 4.197 & 4.277 & 4.215 & \\
\hline C.R. $<0.1$ & 0.056 & 0.077 & 0.069 & 0.096 & 0.075 & \\
\hline
\end{tabular}

Table 3. The final attribute values of Layer $C$ of the wayfinding system.

\begin{tabular}{cc}
\hline Index Layer & Attribute Value \\
\hline Information Accuracy $C_{1}$ & 0.2312 \\
Information Conciseness $C_{2}$ & 0.0284 \\
Categorization $C_{3}$ & 0.0483 \\
Unified Standard $C_{4}$ & 0.0859 \\
Sight Distance $C_{5}$ & 0.0564 \\
Height $C_{6}$ & 0.0188 \\
Color $C_{7}$ & 0.1312 \\
Size $C_{8}$ & 0.2625 \\
Distance Identification $C_{9}$ & 0.0891 \\
Proportional Size $C_{10}$ & 0.0315 \\
Humanistic Care $C_{11}$ & 0.0168 \\
\hline
\end{tabular}

\section{Results}

\subsection{Results of Questionnaire on Tourist Satisfaction}

We adjusted details according to the content and layout of the signboards. To prove the effectiveness of the proposed method, we conducted a questionnaire survey of tourists to Disneyland before and after 
this adjustment. We conducted the survey from 2:00 p.m. to 6:00 p.m. on weekdays and 12:00-20:00 on weekends. A selective (age, gender) survey was carried out for tourists. The on-duty traffic police and traffic service personnel (traffic manager, traffic guide) were also interviewed. A total of 300 tourists were surveyed, where 294 responses were valid for an effective recovery rate of $97.7 \%$. The statistical results show that $80.2 \%$ of the respondents thought that the public information system was essential or very important. The problems recognized by them were deficiencies in each element of the wayfinding system, unreasonable spatial layout of the public information guidance system, and a lack of information transmission between signage and resorts; for instance, there is no follow-up identification information after half the journey.

Having experienced the resort guidance system, most tourists tend to think that it can meet their requirements to a certain extent but has limitations. In 2017, 300 tourists were randomly chosen and interviewed by members of this research team at the Shanghai Disneyland Resort. Ten to 15 questions were asked to test the satisfaction index of the questionnaire survey, corresponding to the 11 evaluation indices of the sign guidance system. The weight of each index was determined by the expert prediction method [34]. The results enable a quantitative estimation in the absence of sufficient statistical data and original data [35].

The scores of the 11 evaluation indicators in the questionnaire survey were as follows. Tourists feel totally incomprehensible, very unsatisfied, very unreasonable, challenging to find, and ultimately not meeting the requirements equal 2 points. Tourists feel incomprehensible, unsatisfactory, unreasonable, and not meeting the requirements equal 4 points. Average feeling equals 6 points. The feeling of understandable, satisfactory, reasonable, accurate, easy to find, and can meet the requirements equal 8 points. If they feel completely understandable, very satisfactory, very reasonable, and meets all requirements then the question can get 10 points.

In the questionnaire survey shown in Table 4 , the weights of the 11 evaluation indices for satisfaction evaluation were determined by the expert estimation method based on quantitative and qualitative analyses. The determined weights of the 11 evaluation indices were as follows: the readability takes $5 \%$, color and font of the sign takes $5 \%$, density of the layout of the sign takes $5 \%$, sight distance and height takes $5 \%$, oriented information density takes $5 \%$, information accuracy takes $20 \%$, convention of sign layout takes $5 \%$, continuity of guidance system takes $10 \%$, indications for important destinations takes $20 \%$, frequency of update of signage information takes $10 \%$, and satisfaction with the guidance system takes $10 \%$.

The average score for tourist satisfaction was $75 \%$, which shows that there were deficiencies in the design of the guidance system for the park. The continuity of the guidance system and convenience of the layout of the signage were found least satisfactory by the respondents.

\subsection{Results of Evaluation of Signage Layout}

\subsubsection{Average Degree of Attractiveness of Indication Guidance (AATT)}

The scoring standard and boundary of the expert survey method are introduced as follows. Based on the discussion results of 20 experts introduced at Section 2, and taking the average score as the benchmark score, the actual score of Shanghai Disneyland Park was calculated and compared:

The calculation method of contrast value is (actual score/benchmark score) $* 100 \%$.

It is concluded that at more than $150 \%$ of the value of the guidance system, the element performance is excellent, between 120 and $150 \%$ is the space for modification and improvement of the factor, $100-120 \%$ is in urgent need of modification, and if the score is less than $100 \%$, it is necessary to redesign. 
Table 4. Questionnaire survey of tourists' satisfaction with signage in Shanghai Disneyland.

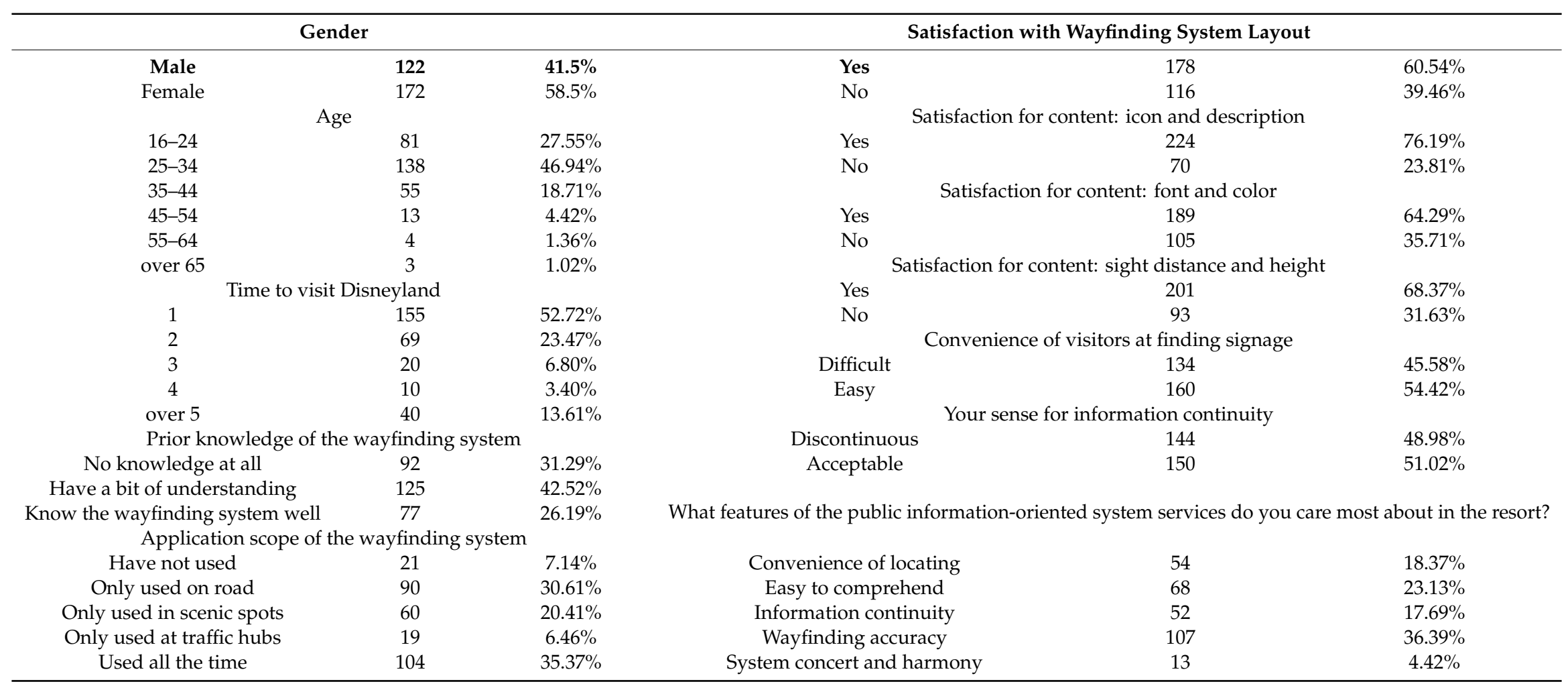


The research objects were divided into three categories: signs indicating scenic spots only, signs indicating service areas only, and signboards indicating entrances and exits. According to the field investigation, the scoring results were as follows: (1) scenic spots takes 0.0305 , and the normalized results were 0.0142 with a percentage of $214.51 \%$; (2) the scores of service area were 0.009 , and the normalized results were 0.006 with a percentage of $151.23 \%$; (3) for entrances and exits, the scores were 0.0179 and 0.0128 , respectively, with a percentage of $139.25 \%$; (4) the overall score was 0.0606 , the normalized result was 0.0337 , and the percentage was $179.93 \%$.

According to the evaluation standard, all the scores of AATT are above $150 \%$, so the conclusion is all three types of the signboards in Shanghai Disneyland perform well in the aspect of indicating visitors to hot scenic spots, and there is almost no information left of popular attractions. That is, we do not need to add other information and elements on the basis of the current sign information as a whole, because this wayfinding system can transfer information perfectly.

\subsubsection{Average Distance of Indication Guidance (ADIS)}

The results for ADIS calculation were as follows. (1) The distance index for scenic spots was 0.7297 , the normalized result was 0.64 , and the percentage was $114.02 \%$; (2) the score for the service area was 0.9021 , the normalized result was 0.79 , and the percentage was $114.19 \%$; (3) taking only the entrances and exits indicated, the score for them was 0.5101 , the normalized result was 0.5733 , and the percentage was $88.98 \%$; (4) the overall score was 2.1419 , the normalized result was 1.4633 , and the percentage was $146.37 \%$.

We can find that the score of average distance is not so good, which indicates that the layout distance between wayfinding signage and tourist attractions, service area, entrances and exits needs to be improved. The reason for the low score of ADIS may be the lack of signboards on the way to destinations, or the lack of related destination information on most of the signboards along the routes [36]. The calculation result recommends that the park implement more intensive setting of relevant destination signage on each indicated route.

\subsubsection{Average Indication Density of Road Where Signs Were Located (ADEN)}

The research objects can be divided into relationships between directional signs and roads only, and those between sketch maps of the plane and the roads. (1) The score for the former was 0.0148 , with a standard value of 0.0086 and a percentage of $171.79 \%$. (2) The score for the latter was 0.08 , with a standard value of 0.0357 and a percentage of $224.07 \%$. According to the number ratio of the two types of signs in Disneyland, the calculation coefficients were 0.8112 and 0.1888 , respectively; thus, the total score was $181.67 \%$.

Combining the score of ADEN and ADIS, which refers, respectively, to the indicating distance between signs and destinations, and the density of road signs, we can conclude that the low score of ADIS and high score of ADEN indicates there is no need to put more signboards along main roads, but the information along the road needs to be related more to destinations if we take economic considerations.

\subsubsection{Average Information Coefficient of Indication Sign Network (AINT)}

The result of the formula for road coverage by the information network was 6.3511, the normalized result was 5.5006, and the percentage was $115.46 \%$.

The calculation result informs the park management staff that the overall layout density of the guide signs in the park is unqualified. Combining the calculation results of the other indicators above, it can be analyzed that it is not due to the insufficient layout of the main roads, so it is more likely to be marked on long roads [37]. This can easily lead to loss of people on non-main roads and unimportant scenic spots whose feelings the designers need to take care of as well [38].

According to the objective data and matrix calculation, the overall identification was adequate which can be found in Table 5, and the identification of guiding signs for the entrance and exit were further strengthened. (1) The identification of popular scenic spots by directional signs was sufficient, 
whereas the identification of entrances and exits could be further strengthened. (2) The guiding distance is the distance between the position of the directional signs and the scenic spots referred to on them. (3) The reasonableness of the density of signs on roads as classified by right of way was generally reasonable and did not need to be adjusted. (4) The density of spacing of guiding signs in this section was adjusted accordingly. The number and density of duplicate signs needed to be reduced to reduce the difficulty of identification for tourists. Additionally, some specific roads needed the addition of the necessary signboards to prevent tourists from feeling lost.

Table 5. Results of calculation of the layout of signage of the Shanghai Disneyland wayfinding system.

\begin{tabular}{ccccccc}
\hline Category & Description & Total Calculation & Total Normalization & Percentage & Conclusion \\
\hline AATT & Spatial Attraction Index & 0.0606 & 0.0337 & $179.93 \%$ & Work well \\
ADIS & Guidance Distance Index & 2.1419 & 1.4633 & $146.37 \%$ & Need improving \\
ADEN & Signage Density Index & - & - & $181.67 \%$ & Work well \\
ADEN $_{\mathrm{Si}}$ & Road Density of Indicating signs & 0.0148 & 0.0086 & $171.79 \%$ & Work well \\
ADEN $_{\mathrm{Sp}}$ & Road Density of Positioning signs & 0.08 & 0.0357 & $224.07 \%$ & Work well \\
AINT & Information Network Index & 6.3511 & 5.5006 & $115.46 \%$ & Adjustment required \\
\hline
\end{tabular}

\subsection{Evaluation of Signage Content}

After calculating the topological indicators, we focused on improving and optimizing the design content on each sign. The results were compared with the scores assigned by the 20 experts group, mentioned at Section 2, of the Shanghai International Tourism Resort, for several types of signboards specified in the standard at Section 3.2. After confirming and collecting the data, we found that the safety signs, brochures, and tourist maps satisfied the tourists' requirements [39]. The experts scored and improved the locational signs, directional signs, and positioning signs according to their percentage score results.

The conclusions that can be drawn from the analysis of signage content are as follows. The informational content of the positioning signs needed to be standardized, and their height could be further adjusted. The positioning signs did not meet the qualification conditions because of their text content. Informational expression should be adjusted to be concise and accurate. The calculation procedure was as follows.

Based on the evaluation results of Table 6, Table 7 and Figure 3, this study found that all the three types of signs need optimizing the presentation of information. Some value is below the standard, and that is the main task for wayfinding system designers to revise. Compared with the standard score of 51.76 , the total score at 58.09 was $112.23 \%$, which is reasonable, but can be improved with improvements in the layout design and unified standard of the text content. As for the self-attribute of the guiding signs, the project evaluates from the four categories of text content, location evaluation, typesetting design, personalization, and nine indicators are used to multiply the weight and score to get the scores of each item. The total score (53.85) was $94.31 \%$ compared with the standard total score (57.10), which was unreasonable. The guiding signs generally failed to meet the requirements in the text content, so it needs to be improved. The total score of 56.78 was $103.89 \%$ compared with the standard total score (54.66). The evaluation was more reasonable; however, the information conciseness and personalized proportion of positioning signs did not meet the requirements. The results show that the overall service level was appropriate, but in view of deficiencies in the wayfinding system, we suggest improvements as well [40]. 
Table 6. Results of the calculation of signage content of the Shanghai Disneyland wayfinding system.

\begin{tabular}{|c|c|c|c|c|c|c|c|c|c|}
\hline Category & $\begin{array}{l}\text { Assessment } \\
\text { Elements }\end{array}$ & $\begin{array}{l}\text { Attribute } \\
\text { Value }\end{array}$ & $\begin{array}{l}\text { Standard } \\
\text { Value }\end{array}$ & $\begin{array}{c}\text { Evaluation } \\
\text { Value }^{1}\end{array}$ & $\begin{array}{c}\text { Calculation } \\
\text { Score }^{1}\end{array}$ & $\begin{array}{c}\text { Evaluation } \\
\text { Value }^{2}\end{array}$ & $\begin{array}{c}\text { Calculation } \\
\text { Score }^{2}\end{array}$ & $\begin{array}{c}\text { Evaluation } \\
\text { Value }^{3}\end{array}$ & $\begin{array}{l}\text { Calculation } \\
\text { Score }^{3}\end{array}$ \\
\hline \multirow{4}{*}{ Text Content (B1) } & Information Accuracy (C1) & 0.2312 & 13.87 & 50 & 11.56 & 80 & 18.49 & 60 & 13.87 \\
\hline & Information Conciseness (C2) & 0.0284 & 1.7 & 50 & 1.42 & 70 & 1.99 & 50 & 1.42 \\
\hline & Unified Standard (C3) & 0.0483 & 2.9 & 70 & 3.38 & 50 & 2.41 & 70 & 3.38 \\
\hline & Categorization (C4) & 0.0859 & 5.15 & 50 & 4.29 & 80 & 6.87 & 80 & 6.87 \\
\hline \multirow{2}{*}{ Text Location (B2) } & Sight Distance (C5) & 0.0564 & 3.39 & 60 & 3.39 & 60 & 3.39 & 60 & 3.39 \\
\hline & Height (C6) & 0.0188 & 1.13 & 70 & 1.32 & 70 & 1.32 & 70 & 1.32 \\
\hline \multirow{2}{*}{ Typesetting Design (B3) } & Color (C7) & 0.1312 & 7.87 & 70 & 9.19 & 60 & 7.87 & 60 & 7.87 \\
\hline & Size (C8) & 0.2625 & 15.75 & 60 & 15.75 & 60 & 15.75 & 60 & 15.75 \\
\hline \multirow{3}{*}{ Disabled Care (B4) } & Distance Recognition (C9) & 0.0891 & 5.34 & 40 & 3.56 & 1 & 1 & 1 & 1 \\
\hline & Proportions (C10) & 0.0315 & 1.89 & 1 & 1 & 1 & 1 & 50 & 1.58 \\
\hline & Humanistic Concern (C11) & 0.0168 & 1.01 & 1 & 1 & 1 & 1 & 80 & 1.34 \\
\hline
\end{tabular}

${ }^{1}$ : Indication Signs, ${ }^{2}$ : Positioning Signs, ${ }^{3}$ : Plate Information Signs.

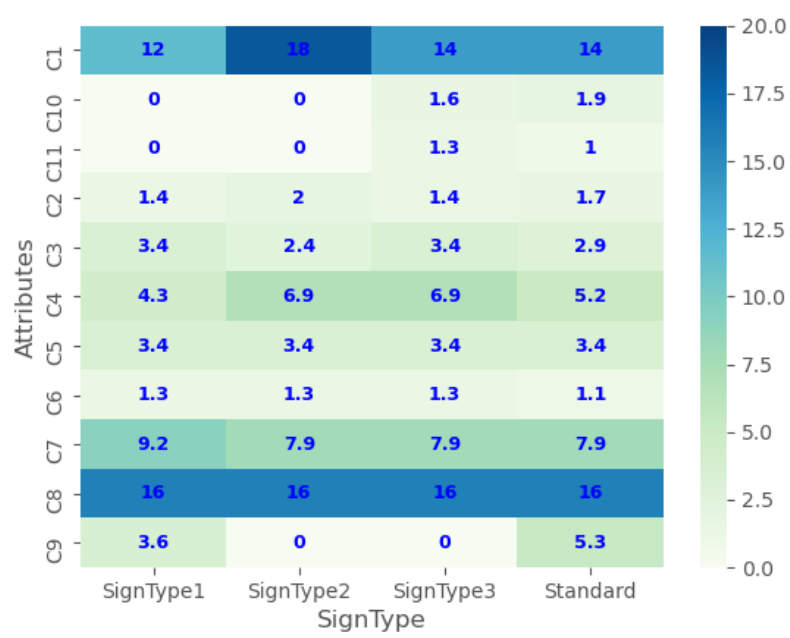

Figure 3. Results for evaluation of signage content in Shanghai Disneyland. 
Table 7. The results for the signage content of the Shanghai Disneyland wayfinding system.

\begin{tabular}{cccc}
\hline Evaluation Results & 1: Indication Signs & 2: Positioning Signs & 3: Plate Information Signs \\
\hline Average Standard Score & 57.1 & 54.66 & 51.76 \\
Average Calculation Score & 53.85 & 58.09 & 56.78 \\
Percentage & $94.31 \%$ & $112.23 \%$ & $103.89 \%$ \\
\hline
\end{tabular}

According to the specific scores of the content and layout of the guidance system, we went to the field to find specific reasons based on the unreasonable scores and proposed the following improvement suggestions for the reference and modification of Shanghai Disneyland.

1. The road name of Caiyun Avenue was not clear, which made it difficult to judge its boundary.

2. The lack of distance indication (such as, the number of kilometers to a specific scenic spot/service area) caused tourists to feel tired and lost.

3. Some directional signs were too close to each other.

4. In the survey, there are three roundabout islands, and there are generally no signs for passers-by to see (the name of the road is printed on the lane, which is dangerous to observe).

5. The lack of positioning signs (Class B) led to a loss of positioning.

6. A lack of bus stops and symptoms in advance of Xingyuan Park.

7. From Shendi West Road to Lantian Avenue and through Disneyland Avenue, there was no hint of Disneyland Avenue.

8. The East, South, and West Shendi Roads were relatively long, and did not contain an appropriate number of road signs.

9. The E7 bus station had a single station, and there was no matching station on the opposite side of the road.

10. The street signs were covered by tree shade, barrier-free signs are blocked by road signs, and the road signs themselves blocked one another.

11. The color, contrast, and text of the road signs were unsatisfactory (not uniform, and the English was small and not easy to read).

\section{Discussion}

During a gradual improvement process from 2017 to 2019, we re-implemented a field survey in Shanghai Disneyland Resort which is shown in Table 8. This time we participated in the survey and randomly checked 50 tourists, which is the same as the 2017 questionnaire. After measuring the content and layout of the guidance system of Disneyland Park, the tourism management department modified and updated the contents of the corresponding signboards. For example, the contents of the signboards generally indicate the distance to the indicated places, unify the font size and scenic spot signs in all parts of the park, adjust the number of signs in the areas where the layout information is too dense or too sparse, and sign letters of main roads and popular scenic spots of interest adjustment, etc. The results of the questionnaire indicate that the reasonable planning based on the two-level model of content and layout improves people's awareness of the design of the guidance system, which is more conducive to tourists to find their way smoothly. It is necessary to select projects with a better foundation and better development prospects for investment and construction to avoid the waste of resources caused by blind installation. Our research result in Figure 4 shows a clear growth of tourist satisfaction is made in both signage content and wayfinding sign layout after this modification task, which proves that through this quantification method, the managers and designers of tourist attractions can improve wayfinding systems to be more scientific and reasonable without unsustainable resource waste. 
Table 8. The questionnaire for tourist satisfaction of the Shanghai Disneyland wayfinding system (investigation in June 2017 and June 2019 ).

\begin{tabular}{|c|c|c|c|c|c|}
\hline Occupation Ratio & Specific Description & Degree of Satisfaction $^{1}$ & Score ${ }^{1}$ & Degree of Satisfaction $^{2}$ & Score ${ }^{2}$ \\
\hline 0.05 & Identity readability & 0.78158 & 0.039079 & 0.8025 & 0.040125 \\
\hline 0.05 & Color and font of the signage & 0.73512 & 0.036756 & 0.7825 & 0.039125 \\
\hline 0.05 & Layout density of the signage & 0.7229 & 0.036145 & 0.8156 & 0.04078 \\
\hline 0.05 & Sight distance and height & 0.75292 & 0.037646 & 0.8326 & 0.04163 \\
\hline 0.05 & Orientated information density & 0.73588 & 0.036794 & 0.7854 & 0.03927 \\
\hline 0.2 & Information accuracy & 0.75898 & 0.151796 & 0.7974 & 0.15948 \\
\hline 0.05 & Signage layout convenience & 0.70718 & 0.035359 & 0.8025 & 0.040125 \\
\hline 0.1 & Guidance system continuity & 0.70106 & 0.070106 & 0.9125 & 0.09125 \\
\hline 0.2 & Indications for important destinations & 0.81564 & 0.163128 & 0.92 & 0.184 \\
\hline 0.1 & Signage information update frequency & 0.7536 & 0.07536 & 0.8075 & 0.08075 \\
\hline 0.1 & Satisfaction to the guidance system & 0.74536 & 0.074536 & 0.7812 & 0.07812 \\
\hline 1 & Total calculation & - & 0.756705 & - & 0.834655 \\
\hline
\end{tabular}

: investigation in June $2017,{ }^{2}$ : investigation in June 2019.

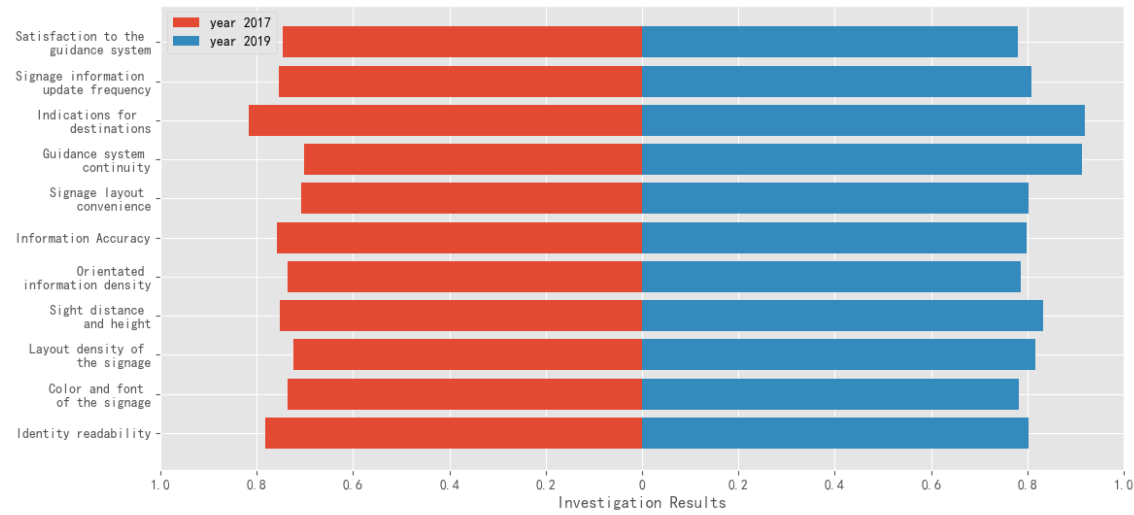

Figure 4. Results for tourist satisfaction investigation in 2017 and 2019 in Shanghai Disneyland. 


\section{Conclusions}

Our research took the wayfinding system for Shanghai Disneyland tourist attractions between the year 2017 to 2019 as the research object, and we proposed a quantification method to score both the content and the layout indices to achieve targeted modification instead of traditional large-scale replacement of signboards. The investigation results show that this method actually worked and has improved tourist satisfaction, which means our index selection and measurement are meaningful, and can be applied to other scenic spots as a reference. Through an analysis of its macroscopic characteristics, calculation of elements of system network topology metrics, and the subjective quantitative research on tourists, the information-oriented wayfinding system was developed further. The understanding and factor analysis further proposed a complete quantitative model for the wayfinding signage system design, evaluation, and optimization of tourist attractions. We assessed the public information guidance system in systematicity, integrity, attractiveness, clarity, distinguishability, accuracy, coordination, rationality, safety of the guidance system, and the principle of people orientation. Through research on the wayfinding signage system of scenic spots, the following research works can be concluded:

(1) We used a combination of objective evaluation and on-the-spot investigation for assessment. The AHP method was used to calculate the content weight of 11 evaluation indices of 3 types of signs in Shanghai Disneyland. Based on the assignment of scores by 20 experts, the qualitative and quantitative evaluations were carried out.

(2) We summarized the macroscopic topological characteristics of the wayfinding system for the given tourist resort. Based on the theoretical theory of topology, the information attraction degree, the density of information, and the distance between signs and destinations, indicators that the labeling system has drawn attention to managers and comparison was taken to demonstrate the flaws precisely. We performed topological calculations and proposed studies on the signboard information.

(3) We have carried out on-the-spot investigations twice and made data collection for the case of Shanghai Disneyland Resort, and according to research, influenced index methods to check whether the preliminary design of the wayfinding system was reasonable, and which specific aspects can be noticed and modified soon. Instead of traditional qualitative methods and fuzzy evaluation methods, this method can be replicated and repeatedly implemented, thereby saving resources and creating precise optimization sustainably.

Author Contributions: Conceptualization, W.Z., L.L., and L.Z.; Methodology, W.Z. and Z.Z. (Zixuan Zhang); Formal Analysis, W.Z. and L.Z.; Investigation, W.Z., L.Z., and Z.Z. (Zixuan Zhang); Writing, W.Z.; Funding Acquisition, Z.Z. (Zhan Zhang). All authors have read and agreed to the published version of the manuscript.

Funding: The National Science Foundation of China partly supported this work (grant no. E080701/51508325).

Acknowledgments: The authors thank the management department of the Shanghai Disneyland Resort for helping explore this subject in inviting experts from related areas and providing map data for signboard locations.

Conflicts of Interest: The authors declare no conflict of interest.

\section{References}

1. Setting Specifications for Public Information Guidance Systems in Tourist Attractions GB/T 31384-2015. Available online: http://www.gb688.cn/bzgk/gb/newGbInfo?hcno=FA5720F5B9478A1ACF768BF857EE30D1 (accessed on 1 September 2019).

2. Lei, B.; Xu, J.; Li, M.; Li, H.; Li, J.; Cao, Z.; Hao, Y.; Zhang, Y. Enhancing role of guiding signs setting in metro stations with incorporation of microscopic behavior of pedestrians. Sustainability 2019, 11, 6109. [CrossRef]

3. Lu, L.; Gu, Z. An evaluation framework for the public information guidance system. KSCE J. Civ. Eng. 2016, 21, 1919-1928. [CrossRef]

4. Ratti, C. Space Syntax: Some Inconsistencies. Environ. Plan. B Plan. Des. 2004, 31, 487-499. [CrossRef]

5. Denis, M.; Michon, P.E.; Tom, A. Applied Spatial Cognition: From Research to Cognitive Technology. In Pedestian Wayfinding in Urban Settings: Why References to Landmarks are Crucial in Direction-Giving; Psychology Press: London, UK, 2006; Chapter 2; pp. 25-52. 
6. Golledge, R.G. Wayfinding behavior-Cognitive mapping and other spatial processes. Psychology 1999, 10, 445-447.

7. Garvey, P.M.; Pietrucha, M.T.; Meeker, D.T. Effects of font and capitalization on legibility of guide signs. Transp. Res. Rec. 1997, 1605, 73-79. [CrossRef]

8. Neurath, O. Basic by Isotype; K. Paul, Trench, Trubner \& Co. Ltd.: London, UK, 1937.

9. Lynch, K. The Image of the City; MIT Press: Cambridge, MA, USA, 1960.

10. Meilinger, T.; Knauff, M. Ask for directions or use a map: A field experiment on spatial orientation and wayfinding in an urban environment. Surveyor 2008, 53, 13-23. [CrossRef]

11. Grabler, F.; Agrawala, M.; Sumner, R.W. Automatic generation of tourist maps. ACM 2008, 27, 1-11.

12. Wiener, J.M.; Büchner, S.J.; Hölscher, C. Taxonomy of human wayfinding tasks: A knowledge-based approach. Spat. Cogn. Comput. 2009, 9, 152-165. [CrossRef]

13. Dai, X.; Tu, H.; Yu, H.; Liu, J. Design of information signs of multi-modal travel at the decision points in a comprehensive transport hub. In Proceedings of the 14th COTA International Conference of Transportation Professionals, Changsha, China, 4-7 July 2014; pp. 1216-1227.

14. Kühl, T.; Stebner, F.; Navratil, S.C. Text information and spatial abilities in learning with different visualizations formats. J. Educ. Psychol. 2017, 10, 104-117. [CrossRef]

15. Schewering, A.; Krukar, J.; Li, R.; Anacta, V.J.; Fuest, S. Wayfinding through orientation. Spat. Cogn. Comput. 2017, 2, 2-28. [CrossRef]

16. Castillo, H.; Pitfield, D.E. ELASTIC-A methodological framework for identifying and selecting sustainable transport indicators. Transport. Res. Part D Transport. Environ. 2010, 15, 179-188. [CrossRef]

17. Bae, Y.H.; Kim, Y.C.; Oh, R.S.; Son, J.Y.; Hong, W.H.; Choi, J.-H. Gaze point in the evacuation drills: Analysis of eye movement at the indoor wayfinding. Sustainability 2020, 12, 2902. [CrossRef]

18. Bodiono, A. Economic application of the theory of graphs. SIAM Rev. 1963, 5, 171-172.

19. Chown, E.; Kaplan, S.; Kortenkamp, D. Prototypes, Location, and Associative Networks (PLAN): Towards a Unified Theory of Cognitive Mapping. Cogn. Sci. 2010, 19, 1-51. [CrossRef]

20. Egenhofer, M.J.; Herring, R.A. Mathematical Framework for the Definition of Topological Relationships. In Proceedings of the 4th International Symposium on Spatial Data Handling, Zurich, Switzerland, 23-27 July 1990; pp. 803-813.

21. Fu, B.; Wu, J.; Chen, X. Research on space syntax application within the city transportation area. Urban Plan. Int. 2009, 24, 79-83.

22. Dobres, J.; Chahine, N.; Reimer, B. Effects of ambient illumination, contrast polarity, and letter size on text legibility under glance-like reading. Appl. Ergon. 2017, 60, 68-73. [CrossRef]

23. Vilar, E.; Rebelo, F.; Noriega, P.; Duarte, E.; Mayhorn, C.B. Effects of competing environmental variables and signage on route-choices in simulated everyday and emergency wayfinding situations. Ergonomics 2014, 57, 511-524. [CrossRef]

24. Mantovani, G.; Gamberini, L.; Martinelli, M.; Varotto, D. Exploring the suitability of virtual environments for safety training: Signals, norms and ambiguity in a simulated emergency escape. Cogn. Technol. Work. 2001, 3, 33-41. [CrossRef]

25. Kansky, K.J. Structure of Transportation Networks: Relationships between Network Geometry and Regional Characteristics; Chicago University: Chicago, IL, USA, 1963.

26. Dubey, R.K.; Thrash, T.; Kapadia, M. Information Theoretic Model to Simulate Agent-Signage Interaction for Wayfinding. Cogn. Comput. 2019, 2,1-18. [CrossRef]

27. Kinateder, M.; Warren, W.H.; Schloss, K.B. What color are emergency exit signs? Egress behavior differs from verbal report. Appl. Ergon. 2019, 75, 155-160. [CrossRef]

28. Classification, Investigation, and Evaluation of Tourism Resources GB/T 18972-2017. Available online: http://www.gb688.cn/bzgk/gb/newGbInfo?hcno=B8AFA5B524438117E00F3BC259B6831C (accessed on 29 December 2017).

29. Frank, H.; Kahn, R.E.; Kleinrock, L. Computer Communications Network Design: Experience with Theory and Practice. Networks 2010, 2, 135-166. [CrossRef]

30. Huang, S.M. A study of reading time and viewers' preferences for a variety of combinations of character-background chromaticity for small traditional Chinese characters. Percept. Mot. Skills 2006, 103, 887-895. [CrossRef] [PubMed] 
31. Saaty, T. The analytic network process: Decision making with dependence and feedback. International 2001, 95, 129-157.

32. Saaty, T.L. Models, Methods E Concepts, and Applications of the Analytic Hierarchy Process; Springer: Boston, MA, USA, 2000.

33. Sudman, S. Asking questions: The definitive guide to questionnaire design for market research, political polls, and social and health questionnaires. J. Mark. Res. 2004, 43, 703-704.

34. Sintonen, H.; Raitio, J.; Honkela, T. Quantifying the effect of meaning variation in survey analysis. In International Conference on Artificial Neural Networks; Springer: Cham, Switzerland, 2014.

35. Gärling, T.; Böök, A.; Lindberg, E. Spatial orientation and wayfinding in the designed environment: A conceptual analysis and some suggestions for post-occupancy evaluation. J. Archit. Plan. Res. 1986, 3, 55-64.

36. Xie, H.; Filippidis, L.; Galea, E.R.; Gwynne, S.; BlackShields, D.; Lawrence, P.J. Experimental study and theoretical analysis of signage legibility distances as a function of observation angle. In Pedestrian and Evacuation Dynamics 2005; Springer: Berlin, Germany, 2007.

37. Andre, A.D.; Koonce, J.M. Spatial Orientation and Wayfinding in Airport Passenger Terminals: Implications for Environmental Design. Proc. Hum. Factors. Ergon. Soc. Annu. Meet. 1991, 35, 561-565. [CrossRef]

38. Shi, Y.; Zhang, Y.; Wang, T.; Li, C.; Yuan, S. The effects of ambient illumination, color combination, sign height, and observation angle on the legibility of wayfinding signs in metro stations. Sustainability 2020, 12, 4133. [CrossRef]

39. Li, Y.; Li, R.; Ruan, W.; Liu, C.-H. Research of the effect of tourism economic contact on the efficiency of the tourism industry. Sustainability 2020, 12, 5652. [CrossRef]

40. Zhou, F.; Zhao, F.; Xu, Q.; Yuan, Y.; Zhang, M. Evaluation and selection methods of tourism characteristic town: The case of Liaoning Province, China. Sustainability 2020, 12, 5372. [CrossRef]

Publisher's Note: MDPI stays neutral with regard to jurisdictional claims in published maps and institutional affiliations. 